\title{
A novel rejuvenation approach to induce endohormones and improve rhizogenesis in mature Juglans tree
}

\author{
Hao Liu' ${ }^{1}$, Ying Gao ${ }^{1,2}$, Xiaobo Song ${ }^{1}$, Qingguo Ma', Junpei Zhang ${ }^{1}$ and Dong Pei ${ }^{1 *}$ (1)
}

\begin{abstract}
Background: Juglans is a difficult-to-root tree. In the present study, we successfully rejuvenated stock plants by grafting and then burying them horizontally.

Results: Rooting rates of rejuvenated shoots were $98.1 \% 20$ days after cutting. We recorded spatial and temporal variation in endogenous indole-3-acetic acid (IAA), abscisic acid (ABA), gibberellin $A_{3}\left(G A_{3}\right)$ and zeatin-riboside (ZR) under root induction. The four types of endohormones were mainly confined to the phloem sieve and companion cells (S\&Cs) at the base of either rejuvenated or mature soft shoots. IAA and ABA levels were higher in rejuvenated shoots than in mature shoots, whereas the opposite was true for $\mathrm{GA}_{3}$ and $\mathrm{ZR}$. During rooting induction, $\mathrm{GA}_{3}$ was the first hormone to be observed outside phloem S\&Cs, followed by IAA, ABA and ZR. In rejuvenating soft shoots, IAA accumulated in the cross-sectional areas of the cambium and phloem, where root primordia were evident.

Conclusions: The improvement in the rooting ability that was evident after rejuvenation most likely results a transformation of the plant to a juvenile form, from elevated IAA levels in phloem S\&Cs and from a promotion of all four endohormones outside phloem S\&Cs, in particular, from an accumulation of IAA in the cross-sectional areas of the cambium and phloem.
\end{abstract}

Keywords: Juglans, Cutting, Rejuvenation, Endohormones, Rhizogenesis

\section{Background}

When trees age, their capacity to form adventitious roots becomes weaker and propagation via cuttings becomes increasingly difficult. From growers' point of view, it is important to improve the adventitious root formation (ARF) capacities of mature trees. Some studies have shown that rejuvenation of mature trees or the induction of plants to regress from maturity to the juvenile state may significantly improve ARF. There are various ways to do this [2], including repeated in vitro subculturing, heavy pruning, mound-layering, serial grafting, and etiolation $[50,53]$. The rooting competences of Sequoia sempivirens and chestnut (Castanea sativa) micro-cuttings

\footnotetext{
*Correspondence: dr_peidong@163.com

1 State Key Laboratory of Tree Genetics and Breeding, Research Institute

of Forestry, Chinese Academy of Forestry, Beijing 100091, China

Full list of author information is available at the end of the article
}

can be restored by serial micro-grafting onto juvenile rootstock in vitro $[19,23]$. The rooting abilities of teak (Tectona grandis) and common walnut (Juglans regia L.) can be improved by stock plant etiolation and exposure to periods of darkness in vitro [25, 38], respectively. In general, walnuts (genus Juglans) are recognized as being difficult-to-root species and even more difficult to propagate from cuttings.

Juvenile and mature trees differ in terms of phenotype, organizational structure and physiology $[8,42]$. Rejuvenation restores the juvenile features of trees, for example, by increasing the activities of esterases and peroxidases [21], and by improving photosynthetic and respiratory rates [22]. Endohormones play important roles in tree rejuvenation. For example, cytokinins and gibberellins can induce rejuvenation and maintain trees in a juvenile state [16, 39]. Huang et al. [24] found that rooting abilities of successive generations of Buxussinica 
var. parvifoli cuttings were associated with changes in the levels of endohormones, including indole-3-acetic acid (IAA), abscisic acid (ABA) and gibberellin $\mathrm{A}_{4}\left(\mathrm{GA}_{4}\right)$. Negishi et al. [34] suggested that IAA/ABA levels reflect the extent of the juvenile phenotype in vitro and the rooting abilities of tender stems. Chang et al. [5] found that glycine-rich RNA-binding proteins accumulate at various rejuvenation stages of Sequoia sempervirens. Their expression is associated with the recovery of rooting ability and is regulated by both auxin and ABA [27, 28]. However, currently, the knowledge about (how or whether) the ARF of trees is improved by rejuvenation or the cytological action modes of various endohormones is quite limited.

The immune colloidal gold technique (ICGT) is a novel method for detecting endohormones in situ. In that method, colloidal gold serves as a marker of antigen-antibody interactions [10, 12-14, 18]. OndzighiAssoume et al. [36] used ICGT to show that ABA levels in the roots of Arabidopsis thaliana change in response to a nitrate treatment. The technique allows synchronous in situ monitoring of serial histological sections, thus being a useful immunohistochemical assay.

In the present study, we used rejuvenation to improve the rooting ability of soft shoots in walnut cultivars. We also subjected serial histological sections to various immunohistochemical assays to investigate spatial and temporal changes in the levels of endogenous IAA, ABA, gibberellin $\mathrm{A}_{3}\left(\mathrm{GA}_{3}\right)$ and zeatin-riboside (ZR). Moreover, we investigated the roles these hormones play to improve rooting by means of rejuvenation.

\section{Results}

\section{Rooting of mature and rejuvenated soft shoots}

After extensive preliminary studies, we found a method to make mature woody plants to be rejuvenated and rejuvenated soft shoots could induce rooting. The protocol is: the cultivar 'Zhongningsheng' [ZNS (Juglans hindsii $\times$ Juglans regia)] stock tree's scions $\rightarrow$ grafted in 1-year-old plants $\rightarrow$ placed these grafted seedlings horizontally and culturing in greenhouse $\rightarrow$ harvest rejuvenated soft shoots $\rightarrow$ adventitious roots induction $\rightarrow$ rooting cultivation in greenhouse (detailed data reference method).

By this method, under the same condition of rooting induction, rooting significantly differed between mature and rejuvenated soft shoots (Fig. 1). In rejuvenated soft shoots, adventitious roots broke through the epidermis after 10 days of induction (Fig. 1c, c1). By day 15, the rooting rate was $92.6 \%$ and the average root number per shoot was 18.3. Adventitious rooting occurred from the basal regions of rejuvenated soft shoots and was longitudinally distributed along the stem (Fig. 1d, d1). By day 20, the rooting rate had reached $98.1 \%$ and the average root number per shoot was 19.7 (Fig. 1e). In contrast, mature soft shoots exhibited no rooting up to day 20 after rooting induction. Only some callus was evident in the basal regions of parts mature soft shoots (Fig. 1f, f1).

\section{Histological observations}

Figure 2 shows the histological differences between rejuvenated and mature soft shoots. Initially, the cortical cells in the basal regions of rejuvenated soft shoots were large and irregular, and separated by a discontinuous sclerenchymal ring from small parenchymal cells (Fig. 2a, b) located between the phloem and the cortex. However, in mature soft shoots, the phloem was surrounded by a continuous sclerenchymal ring, and the cortical cells were small and regular in shape (Fig. 2g). The anatomical structure of mature soft shoots was barely affected by cutting, although the xylem became thicker (Fig. 2h, i).

The histological structure of rejuvenated soft shoots was significantly different after IBA induction, as root primordia developed. On day 4, some cambium cells began to divide, and the cytoplasmic and nuclear densities became elevated (Fig. 2c). After 5 days of induction, dividing meristem cells were evident in the region of the phloem that faced the xylem rays (Fig. 2d). Two days later, initial root primordial cells formed from meristem cells (Fig. 2e). At the same time, small projections became visible on the peripheries of soft shoot bases. Subsequently, root primordia became evident in the phloem (Fig. 2f). On day 9 , proliferations of the secondary phloem broke through the cortex, and the root primordia eventually became visible. Finally, the adventitious root primordia underwent complete development. A dome-shaped root cap formed and the vascular tissue became differentiated (Fig. 2f).

\section{Immunohistochemical localization of endohormones}

Figures 3, 4, 5 and 6 show the immunological locations of IAA, ABA, $\mathrm{GA}_{3}$ and $\mathrm{ZR}$ in rejuvenated and mature soft shoots, and the temporal and spatial changes during adventitious root induction. In rejuvenated and mature cuttings, the four endohormones (IAA, ABA, $\mathrm{GA}_{3}$ and $\mathrm{ZR}$ ) were consistently distributed mainly in the phloem sieve and companion cells (S\&Cs) (Figs. 3a, g, 4a, f, 5a, g, 6a, f). During rooting induction, the endohormones of mature cuttings were always distributed mainly in phloem S\&Cs, while other tissues contained small amounts of IAA, ABA and $\mathrm{GA}_{3}$, and even less $\mathrm{ZR}$ (Figs. 3h, i, 4g, h, 5h, i, 6g, h). However, the endohormone distributions in rejuvenated cuttings changed significantly during rooting induction, unlike what was noted in mature cuttings. At days 1-2 of rooting induction, all four endohormones were mainly distributed in phloem 

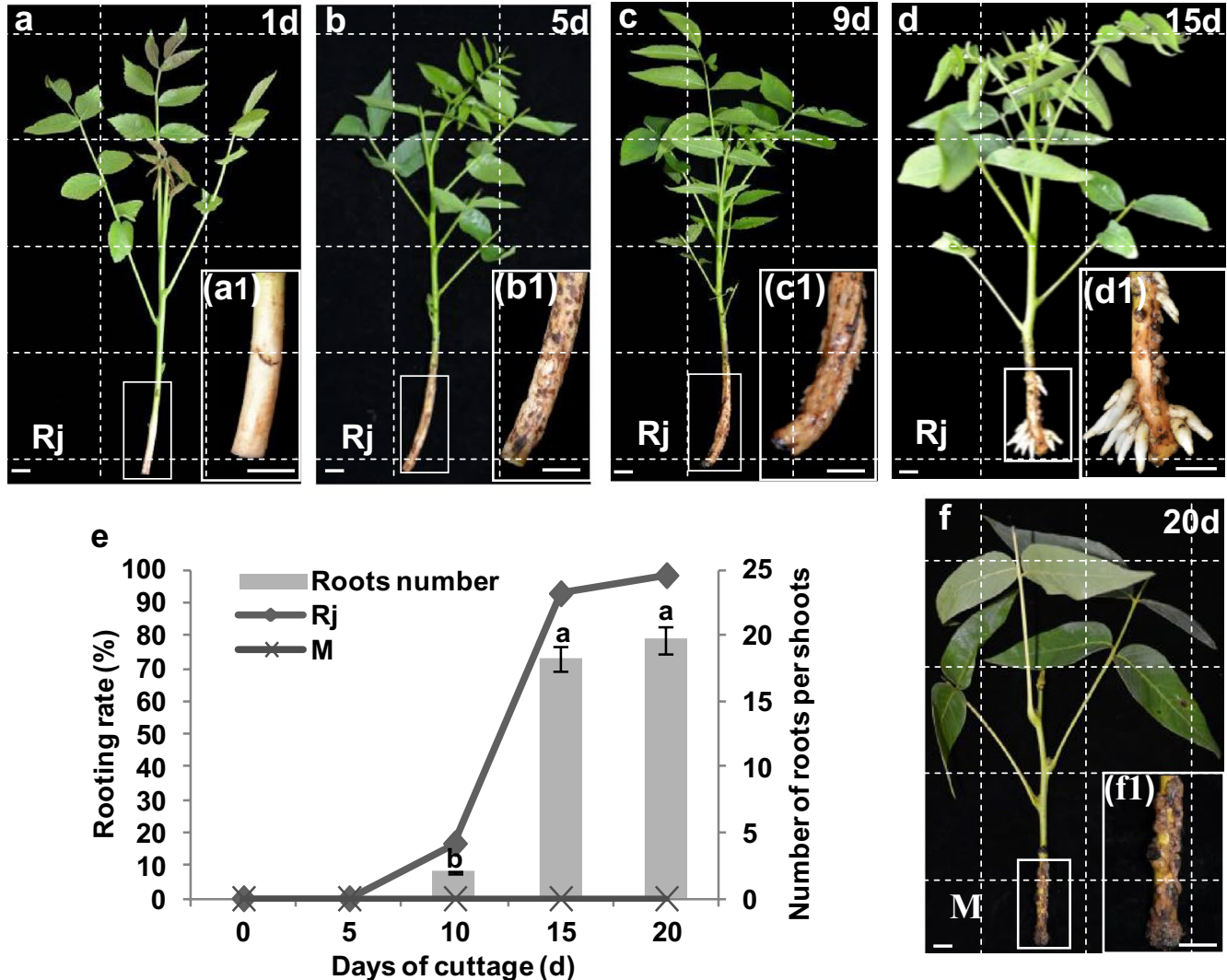

25

20

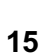

$15 \stackrel{0}{0}$

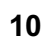

5

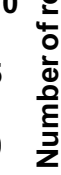
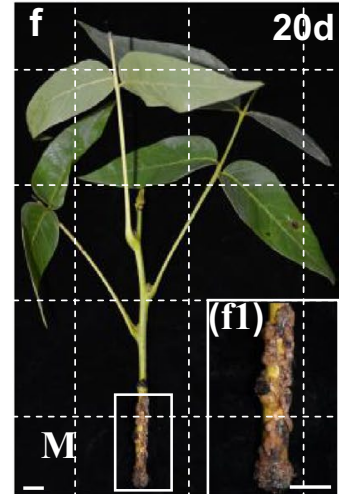

Fig. 1 Rooting data and histological details of ARF in the basal region of soft shoots in walnut. a Rejuvenated soft shoots 1 day after cutting; a 1 color of epidermis was yellow-white. b Rejuvenated soft shoots 5 days after cutting; b1 part of the soft shoots basal epidermis has browned. $\mathbf{c}$ Rejuvenated soft shoots 9 days after cutting; $c 1$ the adventitious roots tip have broken through out the periderm. $\mathbf{d}$ Rejuvenated soft shoots 15 days after cutting; $d 1$ the roots have broken through the epidermis and have assembled along the shoot. e Rejuvenated (Rj) soft shoot and mature (M) soft shoot rooting data, $P<0.05$. f Mature soft shoots 20 days after cutting; $f 1$ no ARF but some callus was evident in the basal regions. Scale bars: $10 \mathrm{~mm}(\mathbf{a}-\mathbf{d}, \mathbf{f})(a 1, b 1, c 1, d 1$ was a twice magnified image respective of the white box in $\mathbf{a}, \mathbf{b}, \mathbf{c}$ and $\mathbf{d})$

S\&Cs. By day $3, \mathrm{GA}_{3}$ was found in the cambium close to $S \& C s$ of phloem (Fig. 5b). By day 4, the cambium had significantly thickened and contained all four endohormones, as did the adjacent ray cells (Figs. 3c, 4b, 5c, 6b). IAA accumulation was particularly obvious. IAA, ABA and $\mathrm{GA}_{3}$ were simultaneously present in some xylem ray cells located near the cambium. By day 5 , adventitious root meristems had formed and the four endohormones were mainly distributed in the meristems, but also in the S\&Cs. IAA, $\mathrm{GA}_{3}$, and $\mathrm{ZR}$ were also present in xylem ray cells (Figs. 3d, 4c, 5d, 6c). By days 6-7, initial root primordial cells had formed and all endohormones were present in these cells. $\mathrm{ABA}, \mathrm{GA}_{3}$ and $\mathrm{ZR}$ were present also in the cambium and phloem (Figs. 3e, 4d, 5e, 6d). By days 8-9, adventitious root primordia of rejuvenated soft shoots had formed and some of them had broken through the epidermis. IAA and $\mathrm{GA}_{3}$ had accumulated close to the root cap. The cambium contained only a little ABA, as did also the root primordia and phloem. ZR became concentrated in the root primordia, and was present also in the phloem (Figs. 3f, 4e, 5f, 6e).

\section{Semi-quantitative analyses on endohormone levels}

Figure 7 lists semi-quantitative measurements of the levels of the four endohormones in rejuvenated and mature soft shoots based on the immunolocalization data, and shows the changes in these levels during root induction. The levels of all four endohormones in the S\&Cs of rejuvenated and mature soft shoots were significantly different. In the S\&Cs of rejuvenated soft shoots, the IODs of IAA and ABA were 43.29 and 153.51, respectively, thus being higher than those of mature soft shoots (IAA 9.55, ABA 52.95). However, in the S\&Cs of rejuvenated soft shoots, the IODs of $\mathrm{GA}_{3}$ (132.63) and $\mathrm{ZR}$ (170.34) were significantly lower than those of mature soft shoots $\left(\mathrm{GA}_{3}\right.$ 348.50, ZR 1059.88). 

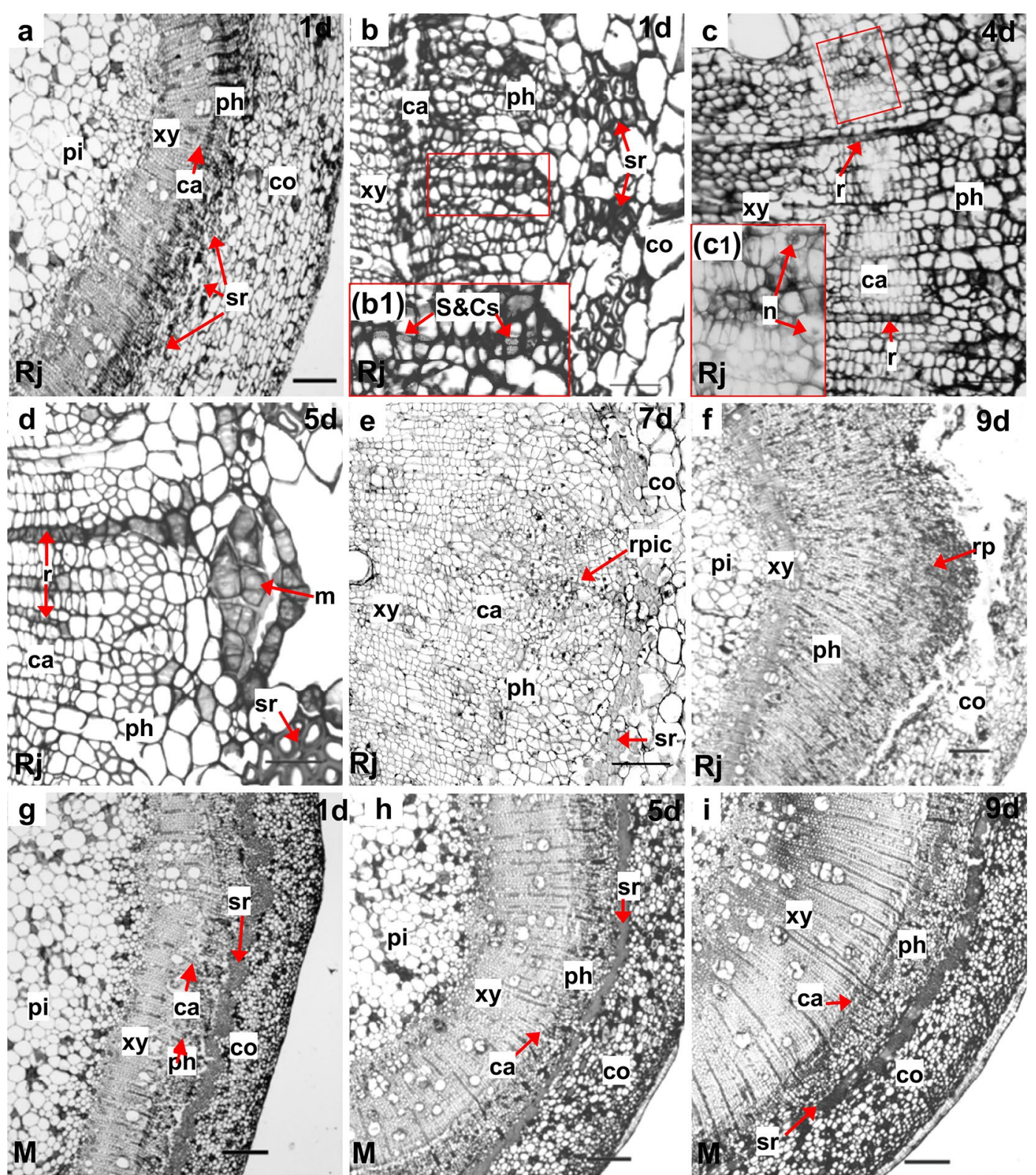

Fig. 2 Histological details of ARF in the basal region of soft shoots in walnut. a-f Transverse sections prepared 1 day (a, b), 4 days (c), 5 days (d), 7 days $(\mathbf{e})$, and 9 days $(\mathbf{f})$ after rejuvenated soft shoots were placed in the rooting medium. $\mathbf{g}$-i Transverse sections of mature soft shoots in walnut prepared 1 day $(\mathbf{g}), 5$ days $(\mathbf{h})$, and 9 days (i) after rooting induction. $\mathbf{a}, \mathbf{b}$ The basal region of the rejuvenated soft shoot contains a discontinuous sclerenchymal ring (arrows). b1 Showing sieve and companion cells (arrows). c Part of cambium is thickened and the nuclei are increased in size (c1: up arrow), some nuclei are in normal size (c1: right arrow). $\mathbf{d}$ Meristem cells located opposite ray cells are dividing. $\mathbf{e}$ The initial cells of the root primordia formed in the outermost region of the phloem. $\mathbf{f}$ Root primordia (the dome-like structures) grown into the cortex. $\mathbf{g}$ The basal region of a mature soft shoot is surrounded by a continuous sclerenchymal ring (arrows). $\mathbf{h}$ The xylem is thickened to about twice of the initial value. $\mathbf{i}$ The xylem becomes thicker over time; the other tissues do not exhibit significant changes. ca cambium, co cortex, $m$ meristems, $n$ nuclei, $p h$ phloem, pi pith, $r$ ray cell, rp root primordia, rpic root primordia initial cells, sr sclerenchyma, S\&Cs sieve and companion cells, xy xylem. Scale bars: $200 \mu \mathrm{m}$ (a $\mathbf{f - i}) ; 100 \mu \mathrm{m}(\mathbf{e}) ; 50 \mu \mathrm{m}(\mathbf{b}-\mathbf{d})(b 1, c 1$ was a twice magnified image respective of the red box in $\mathbf{b}, \mathbf{c})$

During rooting induction, IAA, $\mathrm{ABA}$, and $\mathrm{GA}_{3}$ levels in the cambium and $S \& C s$ of mature soft shoots did not change significantly, whereas the ZR level gradually decreased. However, the levels of all four endohormones in the cambium, $\mathrm{S} \& \mathrm{Cs}$, adventitious root meristems, and initial root primordial cells of rejuvenated soft shoots significantly changed over time. In the cambium cells, the changes in IAA and $\mathrm{GA}_{3}$ exhibited similar trends, 


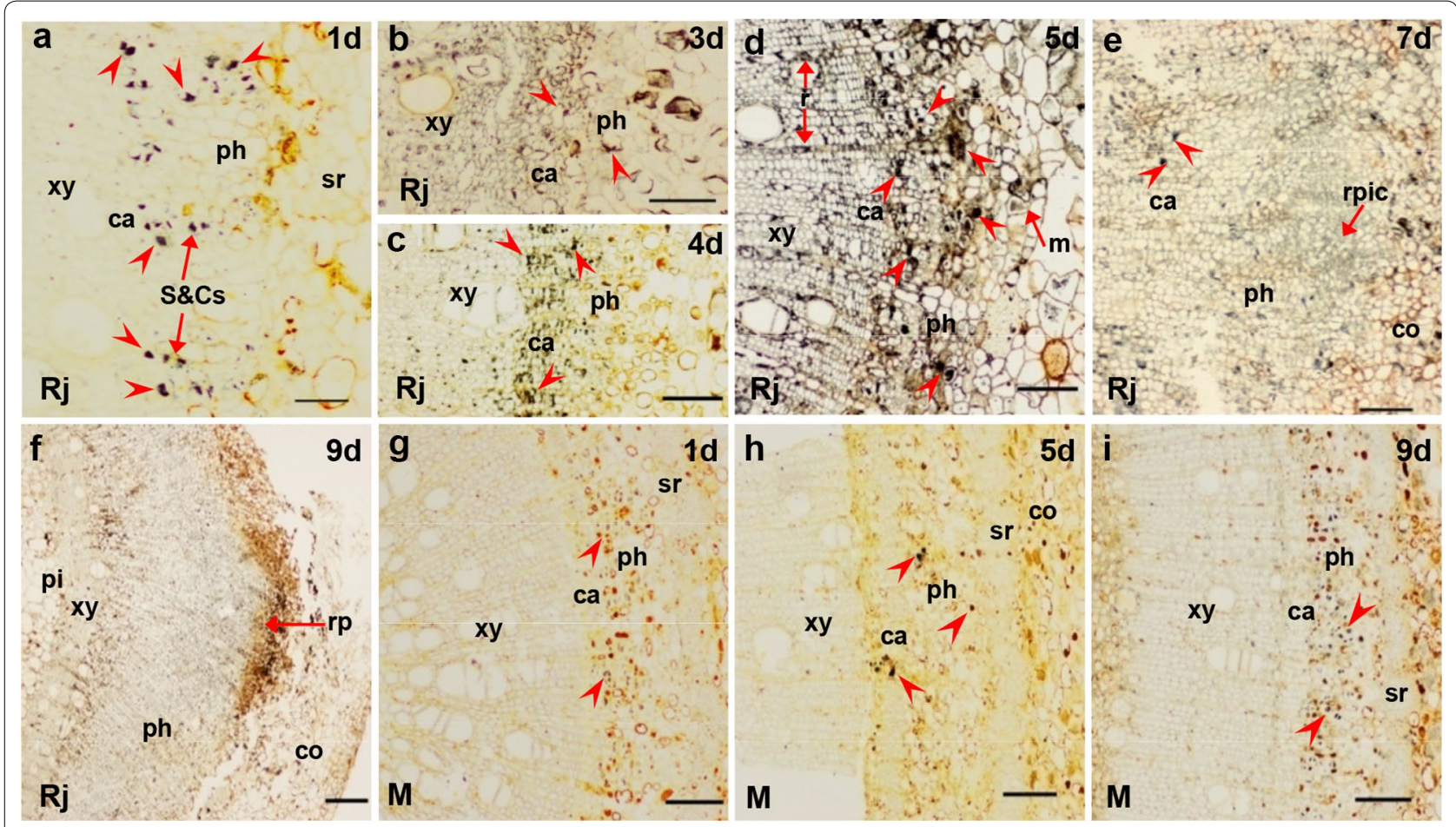

Fig. 3 IAA immunolocalization in the stem bases of rejuvenated and mature soft shoots. a-f Transverse sections of rejuvenated soft shoots in walnut. a, b IAA is located in the stem 1-3 days after induction, but only in sieve cells and companion cells. c By 4 days, as the cambium thickens, IAA concentrates in this tissue. $\mathbf{d}$ By day 5, some meristem cells have divided and IAA is distributed in the meristems and ray cells. e IAA is present less in the initial cells of root primordia, part of cambium and S\&Cs by 7 days. $\mathbf{f}$ The root primordia form by 9 days. IAA is distributed in the primordia, particularly in the tip regions. $\mathbf{g}$-i IAA in the basal regions of mature soft shoots after 1 day $(\mathbf{g}), 5$ days (h), and 9 days (i) of rooting induction. IAA signal is low at those times. The arrows indicate IAA signals. Arrowheads indicate the tissue structure. ca cambium, co cortex, $m$ meristem, ph phloem, $r$ ray cell, rp root primordia, rpic root primordia initial cells, S\&Cs sieve and companion cells, sr sclerenchyma, xy xylem. Scale bars: $200 \mu \mathrm{m}(\mathbf{e}) ; 100 \mu \mathrm{m}$ $(\mathbf{b}-\mathbf{d}, \mathbf{f}-\mathbf{i}) ; 50 \mu \mathrm{m}(\mathbf{a})$

peaking rapidly at days $1-4$. The IOD of IAA increased from 26.07 to 134.03 , and that of $\mathrm{GA}_{3}$ increased from 44.00 to 110.57 but then decreased to 88.87 . However, $A B A$ and $Z R$ levels essentially did not change. In S\&Cs, the trends of changes in IAA, $\mathrm{GA}_{3}$ and $\mathrm{ZR}$ levels were consistent, exhibiting gradual increases until peaking on day 5 , and then decreasing. The ABA level first fell, then increased, and finally decreased again. On day 1 , the IOD of ABA was 153.51, then it fell to 52.63 by day 4, increased to 115.62 by day 5 , and then decreased again. As the adventitious root meristems formed, the levels of all four endohormones significantly increased in this tissue, the IODs of IAA, ABA, GA $\mathrm{GA}_{3}$ and $\mathrm{ZR}$ became 283.88 , 147.96, 410.38 and 451.13, respectively. As the adventitious root meristems developed into adventitious root primordia, the levels of IAA, ABA and $\mathrm{GA}_{3}$ gradually decreased, whereas that of ZR gradually increased.

\section{Discussion}

\section{Rejuvenation and soft-shoot rooting}

Juvenile trees usually have vigorous, upright growth habits and exhibit strong resistance to stress, and their rooting ability is powerful. As trees mature, these characteristics are gradually lost, and the ARF capacity of cuttings gradually decreases [41]. Certain rejuvenation treatments, such as repeated subculture in vitro, grafting onto juvenile rootstock, application of growth regulators, heavy pruning, and cutting to promote coppice shooting or root tiller development, may restore or improve ARF of mature trees. For example, Giovannelli and Giannini [19] found that the rooting rate increased from less than $10-70 \%$ in mature Castanea sativa grafted four times onto juvenile rootstocks, followed by 24 explant subcultures in vitro. Falasca et al. [15] reported that the walnut rooting rate was only $12 \%$ after 4 years of subculture in the presence of IBA. However, placing samples in the dark prior to rooting induction can significantly improve the rooting rate [48]. Petridou and Voyiatzis [40] reported that the rooting rate of the difficult-to-root cultivar Kalamon of Olea 


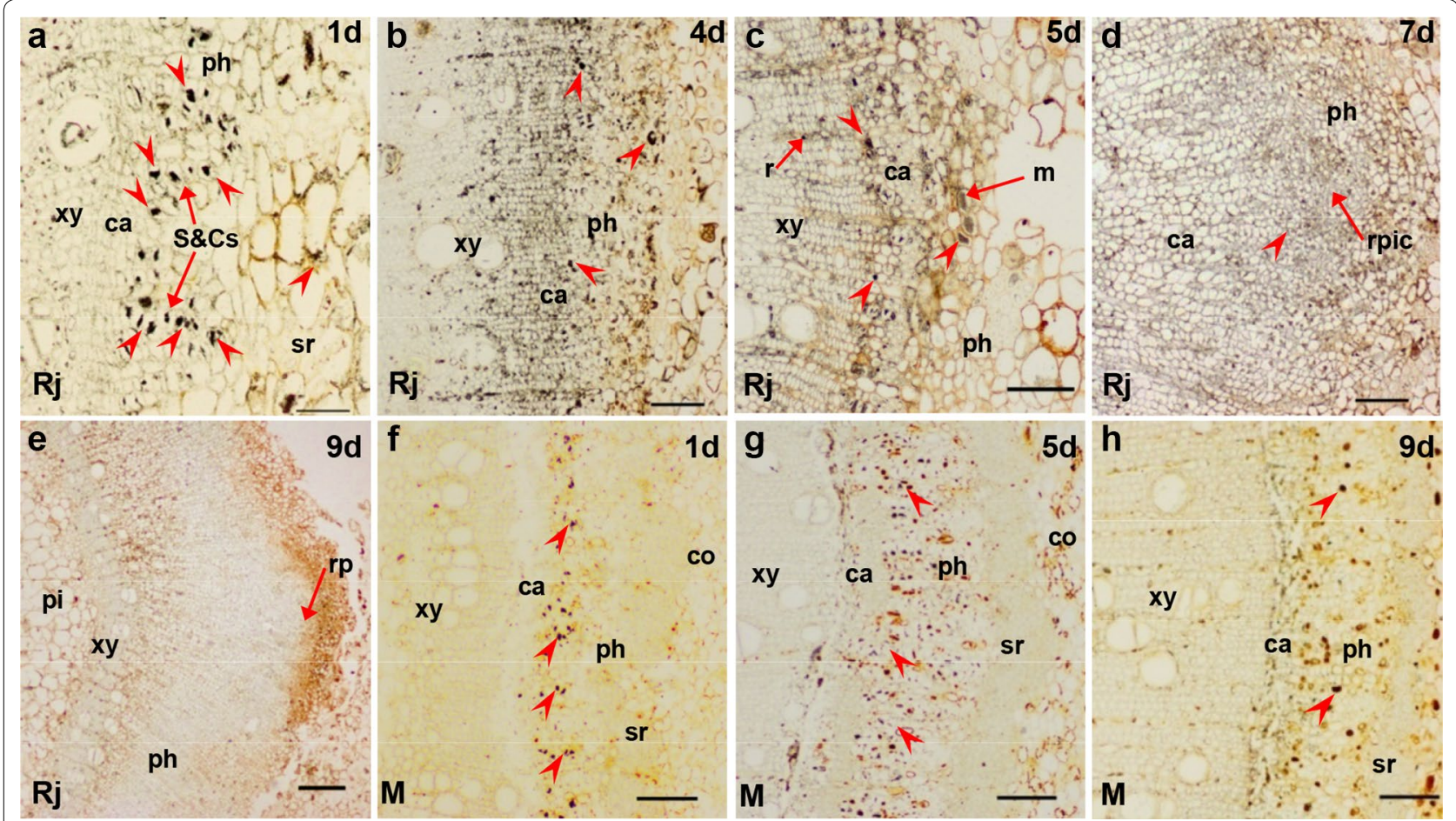

Fig. 4 ABA immunolocalization in the stem bases of rejuvenated and mature soft shoots. a-e Transverse sections of rejuvenated soft shoots in walnut. a After 1 day of induction, ABA was found in S\&Cs. b By 4 days, as the cambium thickened, ABA signal was concentrated in the cambium. $\mathbf{c}$ By 5 days, some meristem cells had divided and the ABA signal was located mainly in the meristem cells, part of cambium and ray cell. d By 7 days, some ABA signals were evident mainly in S\&Cs and surrounding tissue of the initial cells of the root primordia. $\mathbf{e}$ The ABA level in root primordia formed by 9 days was minimal, comparison with supplementary (Additional file 1: Fig. $51 \mathrm{c}$ ), the dark color at the tip of the primordium were not ABA signals. $\mathbf{f}-\mathbf{h}$ ABA signals from the bases of mature soft shoots; 1 day $(\mathbf{f}), 5$ days $(\mathbf{g})$, and 9 days $(\mathbf{h})$. The temporal and spatial patterns of ABA expression did not change. The arrows indicate ABA signals. Arrowheads indicate the tissue structure. ca cambium, co cortex, $m$ meristem, ph phloem, rp root primordia, rpic root primordia initial cells, S\&Cs sieve and companion cells, sr sclerenchyma, xy xylem. Scale bars: $200 \mu \mathrm{m}(\mathbf{e}) ; 100 \mu \mathrm{m}$ $(\mathbf{b}-\mathbf{d}, \mathbf{f}-\mathbf{h}) ; 50 \mu \mathrm{m}(\mathbf{a})$

europaea reached $86 \%$ when harvested softwood cuttings were subjected to mound-layering. Upon such treatment, the rooting rate of 3-year-old walnut seedlings can attain $40 \%$ [49]. In the present study, we showed that a combination of grafting and burying of stock plants horizontally effectively improve ARF of mature walnut plants, the rooting rate of soft shoot cuttings reached 98.2\% (Fig. 1e). This method has also been successfully used to rejuvenate Castanea sativa, Diospyros kaki and Liriodendron chinensis, not only Juglans regia, with rooting rates greater than $90 \%$ in the first three species. The method thus commonly improves ARF of mature trees.

\section{Organizational structure changed by rejuvenation}

We also found rejuvenation induces changes in the organizational structure of mature soft shoots. The most obvious change is that the extent of the sclerenchyma diminishes, and the tissue becomes discontinuously distributed (Fig. 2b, g). Some previous studies have suggested that the formation of discontinuous sclerenchyma tissue is beneficial to rooting, the treatment of etiolation will lead to discontinuous sclerenchyma tissue [33], and the cultivar differences also result in similar results [1]. Our findings indicate that there may be a link between the continuity of sclerenchyma tissue and the plant age (i.e., rejuvenation and mature).

\section{Soft-shoot rooting and endohormone characteristics}

The levels of endogenous hormones in soft shoots changed after grafting and horizontal burying of stock plants. Our immunolocalization data showed that IAA, $\mathrm{ABA}, \mathrm{GA}_{3}$ and $\mathrm{ZR}$ were mainly distributed in phloem S\&Cs of soft shoots (Figs. 3a, 4a, 5a, 6a). Earlier studies have shown that IAA is mainly distributed in cambium cells during the rooting induction of the poplar petiole $[12,13]$ and in the cambium cells of easy-to-root Eucalyptus grandis [9]. The distributions of IAA and other hormones in the tissues of soft shoots may reflect the ability of trees to form adventitious roots. During rooting induction, IAA that accumulates in the cambium cells of 


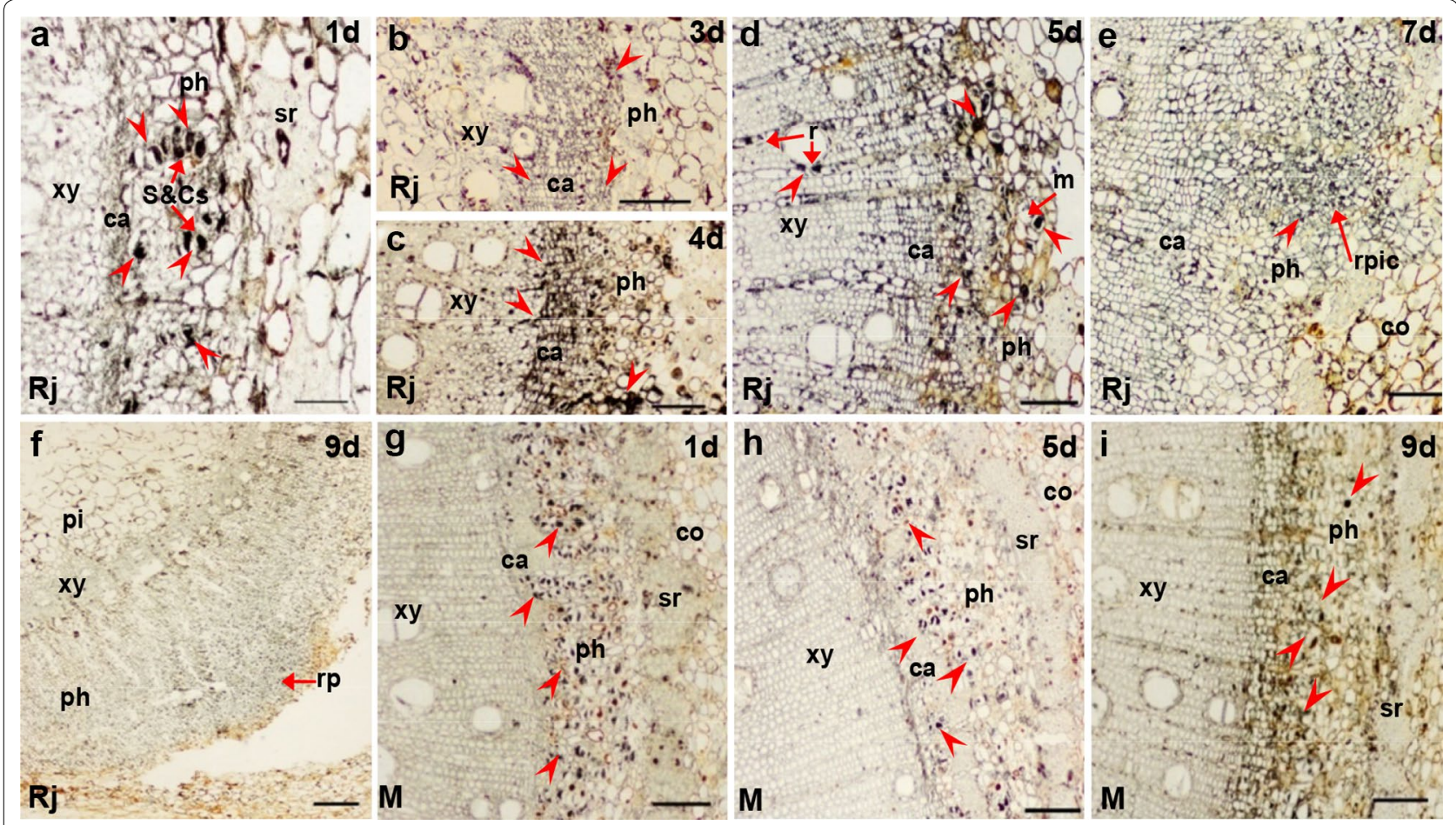

Fig. $5 \mathrm{GA}_{3}$ immunolocalization in the stem bases of rejuvenated and mature soft shoots. $\mathbf{a}-\mathbf{f}$ Transverse sections of rejuvenated soft shoots in walnut. $\mathbf{a} \mathrm{GA}_{3}$ was located in the sieve and companion cells of the stem after 1 day of induction. $\mathbf{b}$ By 3 days, $\mathrm{GA}_{3}$ signal began to appear in the cambium, but remained mainly distributed in sieve and companion cells (S\&Cs). c By 4 days, as the cambium thickened, the $\mathrm{GA}_{3}$ signal became concentrated in the phloem and cambium, particularly along the ray cells. $\mathbf{d}$ By 5 days, some meristems cells had divided and the $G A_{3}$ signals were distributed among meristems, S\&Cs and ray cells. e By 7 days, $\mathrm{GA}_{3}$ signals were evident in the initial cell root primordia, $S \& C s$ and the cambium. f $\mathrm{GA}_{3}$ signals were widely distributed in the root primordia by 9 days. $\mathbf{g}-\mathbf{i} \mathrm{GA}_{3}$ signals in the bases of mature soft shoots on day 1 (g), 5 (h), and 9 (i), GA 3 was located mainly in the S\&Cs of the phloem, by 9 days (i), signal were evident in part of cambium. The arrows indicate the GA, signals. Arrowheads indicate the tissue structure. ca cambium, co cortex, $m$ meristem, ph phloem, pi pith, rray cell, rp root primordia, rpic root primordia initial cells, S\&Cs sieve and companion cells, sr sclerenchyma, xy xylem. Scale bars: $200 \mu \mathrm{m}(\mathbf{e}) ; 100 \mu \mathrm{m}(\mathbf{b}-\mathbf{d}$, f-i); and $50 \mu \mathrm{m}(\mathbf{a})$

poplar or eucalyptus acts directly on these cells. In the soft shoots of walnut, the endohormones are mainly distributed in phloem $S \& C s$ and thus cannot act directly in cambium cells, which may explain why walnut is more difficult-to-root than poplar or eucalyptus.

The levels of IAA and ABA were significantly higher in rejuvenated soft shoots $S \& C s$ of walnut than in mature soft shoots, whereas the opposite was true for $\mathrm{GA}_{3}$ (S\&Cs) and ZR (S\&Cs and cambium) in soft shoots (Fig. 7). Endogenous hormonal status and associated molecular mechanisms are altered when mature cuttings are grafted onto juvenile rootstock, for example, after grafting, the IAA content of new shoots germinating from walnut scions increases [44]. In addition, changes in branch polarity affect the distributions of endogenous hormones, and consequently, lateral bud germination and the hormone levels of new shoots. The original polar gradients of endogenous IAA and GA were changed after branch bending in apple [56], walnut [52], and plum trees [6]. Hormonal spread from the shoots to the base aids the germination of lateral and hidden buds, and the IAA and GA contents decrease in the shoot apices, whereas the ABA and ZR distributions exhibit opposite patterns [56]. Mound-layering affects the physiological state of the hazelnut after bud germination. We used in situ hormonal evaluations to show that the hormone levels of rejuvenated soft shoots of walnut changed upon grafting and horizontal burying of stock plants. The level of endogenous IAA, which aids rooting, rose, whereas the level of $\mathrm{GA}_{3}$, which reduces rooting, decreased. Thus, rejuvenation affected ARF by varying the hormonal levels in soft shoots.

\section{The spatial and temporal modifications of endohormones by rejuvenation to improve rhizogenesis}

The levels of hormones, particularly IAA, outside phloem S\&Cs, especially in the outer layer of the cambium, increased significantly upon rejuvenation (Figs. 3c, d, 7a). IAA accumulation in the cambium is the principal trigger of improvements in the rooting ability of soft shoots of 


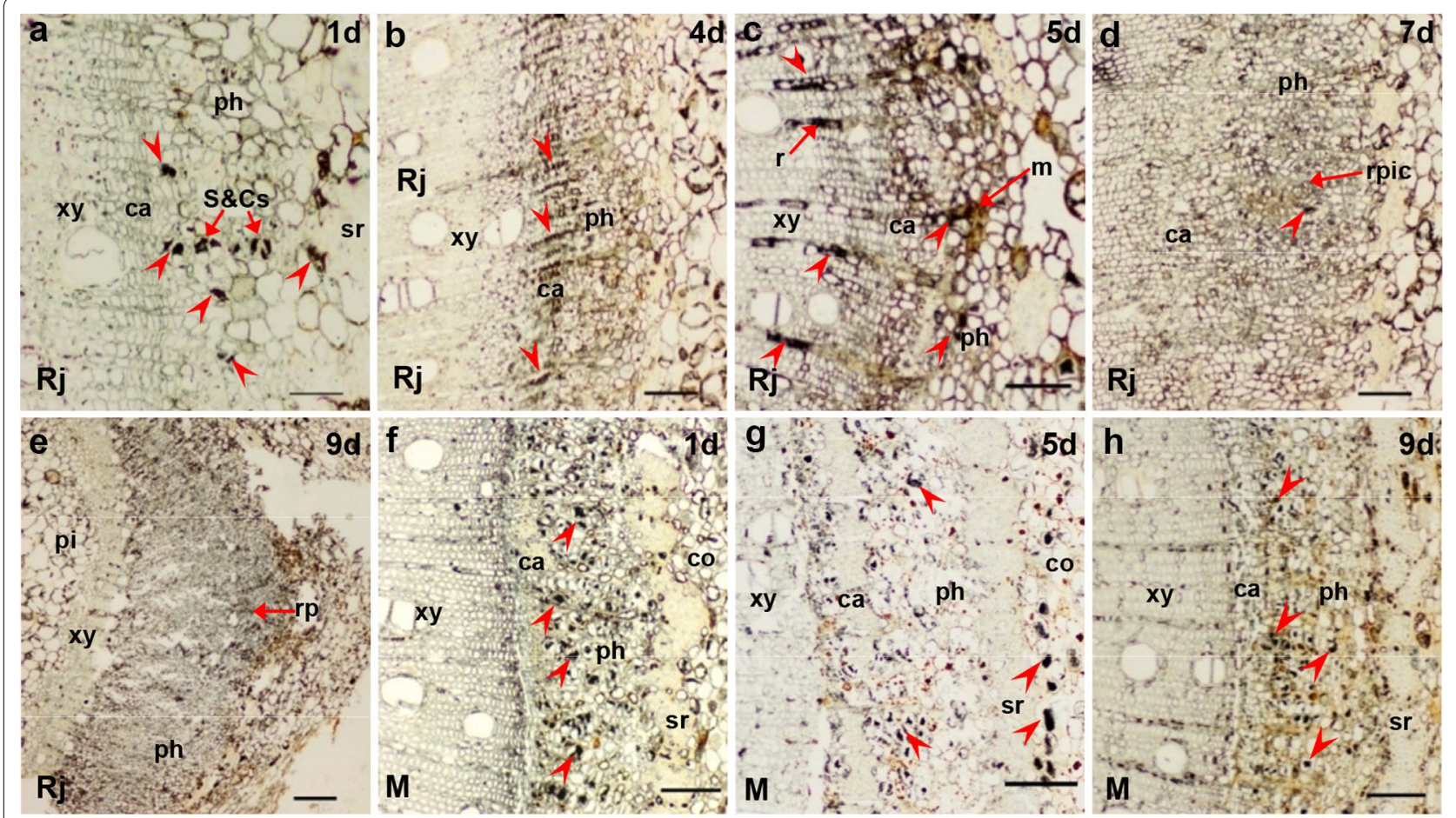

Fig. 6 ZR immunolocalization in the stem bases of rejuvenated and mature soft shoots. a-e Transverse sections of rejuvenated soft shoots in walnut. a On 1 day of induction, ZR signals were located mainly in S\&Cs. b By 4 days, as the cambium thickened, ZR became mainly concentrated in the phloem and cambium, particularly along ray cells. c By 5 days, some meristem cells had divided and the ZR signals were distributed among meristems, S\&Cs and ray cells. $\mathbf{d}$ By 7 days, ZR signals were more evident in the initial cells of the root primordia, but less evident in cambium and S\&Cs. e ZR signals were widely distributed in the phloem and root primordia by 9 days. $\mathbf{f}-\mathbf{h}$ ZR was present more evident in S\&Cs, but not so much in cambium of mature soft shoots on day 1 (f) and $5(\mathbf{g})$. f ZR signals were observed between the xylem and the cambium by 5 days. $\mathbf{g}$ ZR signals were observed in the cortex by 5 days. $\mathbf{h}$ ZR signals were observed in ray cells by 9 days. The arrows indicate the ZR signals. Arrowheads indicate the tissue structure. ca cambium, co cortex, $m$ meristem, ph phloem, pi pith, $r$ ray cell, $r p$ root primordia, rpic root primordia initial cells, S\&Cs sieve and companion cells, sr sclerenchyma, xy xylem. Scale bars: $200 \mu \mathrm{m}(\mathbf{e}) ; 100 \mu \mathrm{m}(\mathbf{b}-\mathbf{d}, \mathbf{f}-\mathbf{h})$; and $50 \mu \mathrm{m}(\mathbf{a})$

walnut. During rooting induction, the four hormones of mature soft shoots were concentrated in the S\&Cs, being rare in other tissues. In rejuvenated soft shoots created by grafting and horizontal burying of stock plants, $\mathrm{GA}_{3}$, IAA, ABA and ZR soon appeared in tissues other than phloem S\&Cs. By day 4 of rooting induction, the endohormones were present in the outer layer of cambium parenchymal cells opposite the pith (Figs. 3c, 4b, 5c, 6b). However, it remains unclear whether the increased levels of endohormones outside phloem S\&Cs reflect hormonal transport from other tissues or synthesis in situ. Some authors have suggested that ARF is closely associated with polar hormonal transport. Dong et al. [12, 13] found that ARF is significantly inhibited by an auxin transport inhibitor (TIBA, 2, 3, 5-triiodobenzoic acid), and a later study showed that TIBA affected the IAA accumulation in the vascular bundles and explant base. Thus, it is possible that the high IAA concentration required for ARF is attributable to transport rather than in situ synthesis. Sukumar et al. [45] found that ARF in
Arabidopsis thaliana hypocotyls requires intact shoot apical meristems and polar IAA transport. Dawood et al. [7] showed that an auxin polarity transport inhibitor (NPA, N-1-naphtylphtalamic acid) significantly reduces the number of adventitious roots produced by Solanum dulcamara and prolongs the duration of ARF.

Based on our results, hormonal transport may have a role. During rooting induction of rejuvenated soft shoots in walnut, $\mathrm{GA}_{3}$ appears earlier in tissues outside of phloem S\&Cs than do IAA and the other endohormones (Figs. 3b, c, 5b, c). This may affect the transport and distribution of the other endohormones, particularly IAA. GAs may improve stem IAA levels by stimulating polar auxin transport [3]. In a study on $\mathrm{GA}_{3} / \mathrm{IAA}$ interactions, Willige et al. [54] found that $\mathrm{GA}_{3}$ affected the level and distribution of the PIN protein on the cell membranes of root meristems in Arabidopsis thaliana, changing the IAA distributional pattern and affecting root gravitropism. Similarly, in a study on Arabidopsis thaliana root gravitropism, Löfke et al. [30] found that 

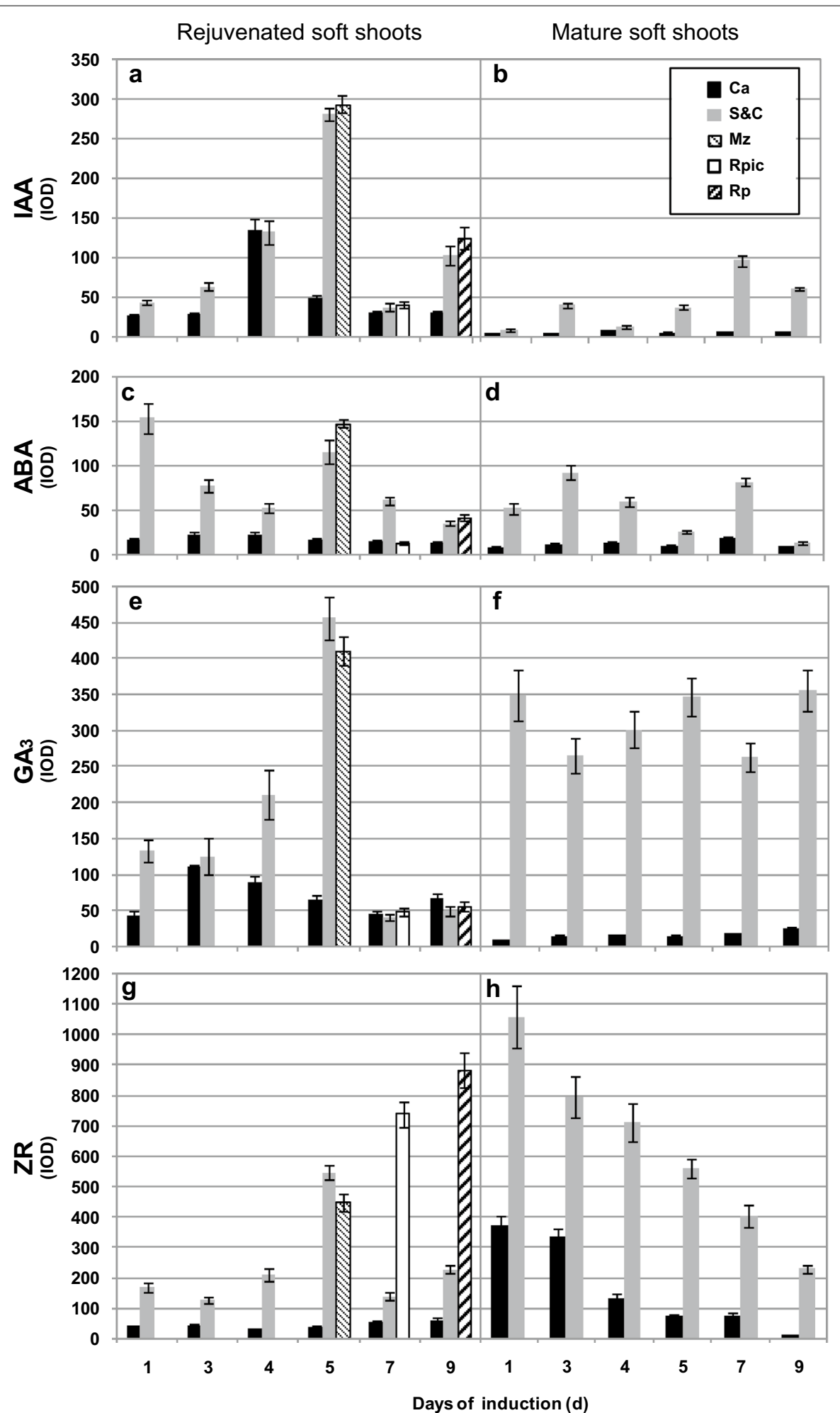

Fig. 7 Integrated optical density (IOD) changes in rejuvenated and mature soft shoots. Rejuvenated soft shoots (a, $\mathbf{c}, \mathbf{e}, \mathbf{g})$ and mature soft shoots $(\mathbf{b}, \mathbf{d}, \mathbf{f}, \mathbf{h})$ reflect changes in IAA, ABA, GA 3 and ZR levels during ARF. Ca cambium, S\&Cs sieve and companion cells, Mz meristem zone, Rpic root primordia initial cells, $R p$ root primordia 
$\mathrm{GA}_{3}$ played an important role in controlling auxin location, polar transport and the carrier PIN protein level in the plasma membrane. During root gravitropism, the auxin accumulation in developing roots required the asymmetric distribution of $\mathrm{GA}_{3}$. In tobacco (Nicotiana tabacum) plants expressing $\mathrm{GA}_{3}$ either constitutively or in specific tissues, the precise localization of $\mathrm{GA}_{3}$ in the stem is required to regulate the adventitious root development. The emergence of root primordia requires a certain level of $\mathrm{GA}_{3}$, the signaling of which is removable [35]. Physiological studies have shown that interactions between GAs and IAA play important regulatory roles in plant development. During adventitious root induction, the fact that GAs accumulate in the cambium earlier than other endohormones may be of a biological importance, and deserves a detailed study.

IAA plays a principal role in adventitious rooting [37, 43]. In this study, IAA became concentrated in the cambium of rejuvenated soft shoots that had thickened 4 days after cutting, mainly in the outer parenchymal layer opposite the pith rays (Fig. 3c). As the root meristems developed, IAA became concentrated in the root primordial cells 5 days after cutting (Fig. 3d). De Almeida et al. [9] have suggested that IAA transforms cambium cells into root primordia. Liu et al. [29] and $\mathrm{Hu}$ and $\mathrm{Xu}$ [20] have proposed that two main cellular transition steps are required to establish root primordia during de novo root organogenesis in Arabidopsis leaf explants. During root primordia formation, WOX11/12 and WOX5/7 are key genes, and auxin acts upstream of WOX5/7 and the polar auxin transport to the wounded region is required for the activation of WOX5/7 by WOX11/12.

$\mathrm{ABA}, \mathrm{GA}_{3}$ and cytokinins influence ARF by interacting with IAA [55]. ABA is required for ARF, but high ABA levels inhibit this process [26, 31]. Tartoura [46] applied exogenous ABA to Vigna radiata cuttings during the initiation of ARF and found that the IAA peak was delayed and the length of rooting induction was extended. In our study, the ABA level was always low in the cambium of rejuvenated soft shoots (Fig. 7c). Huang et al. [24] measured ABA contents (using an enzymelinked immunosorbent assay) during rooting in Buxussinica var. parvifolia. Prior to the rooting initiation, the ABA level gradually decreased in continuous successive generations and reached a lower concentration compared to other hormones. Generally, it is believed that high GA levels inhibit ARF [4]. Our finding showing that the $\mathrm{GA}_{3}$ level was lower in the cambium of rejuvenated soft shoots than in mature soft shoots during the induction of root primordia is consistent with this view (Fig. 7e, f). In a hybrid aspen, Mauriat et al. [32] found that plants overexpressing the key gibberellin biosynthesis gene AtGA20ox1 grew rapidly but exhibited poor rooting efficiency. GAs appears to compromise ARF by modulating the polar auxin transport. Cytokinins are thought to inhibit rooting by interacting with auxin. In our study, the ZR level was low in soft shoots after rejuvenation but clearly higher during the period of formation of cells of the root primordia, no change was evident prior to this period (Fig. 7g). In a study on Arabidopsis ARF, DellaRovere et al. [11] found that cytokinins affected auxin biosynthesis and transport by inhibiting the $L A X 3$ and PIN1 expression, thus regulating the formation of the quiescent center of the root tip, consistent with the presence of $\mathrm{ZR}$ in the central cells of the root primordia in the soft shoots of walnut.

\section{Endohormone model of rejuvenation in Juglans tree rhizogenesis}

The in situ analysis allowed us to propose how endohormones improve the rooting ability of rejuvenated soft shoots of walnut (Fig. 8). Rejuvenation enhances the IAA level in the S\&Cs of soft shoots, and notably elevates endohormone accumulation by the outer cambium cells during rooting. Specifically, during early root induction, the four endohormones are essentially confined to phloem S\&Cs. The levels of $\mathrm{GA}_{3}$, IAA and ZR increase in the outer cells of the cambium and the cambium becomes thicker. Next, the four endohormones become concentrated in the outer parenchyma cells of the cambium, opposite the pith rays, and these cells divide and differentiate to form root meristems. Finally, the endohormones are present in this tissue and the root meristems develop into root primordia. However, technical constraints prevented us from defining the temporal and spatial features of endohormones distributions in root meristems. This is essential knowledge when trying to understand how endohormones regulate ARF.

\section{Methods}

\section{Plant material and root induction}

We used the walnut cultivar 'Zhongningsheng' [ZNS (Juglans hindsii $\times$ Juglans regia)]. The stock tree was 23 years old, had exhibited steady reproductive growth and is located in the Luoning county, Henan province. Rejuvenated soft shoots of ZNS were obtained as follows: first, new ZNS shoots from the stock tree (scions) were grafted to rootstock (1-year-old seedlings). Then, 1-yearold grafted plants were brought into the greenhouse and placed horizontally under $4-5 \mathrm{~cm}$ of clean wet sand to ensure maximum shoot bud break. The humidity was held at $50 \%$, the greenhouse used natural light, and the sand temperature was held at $15 \pm 5^{\circ} \mathrm{C}$. After $60-70$ days of culturing, the rejuvenated soft shoots were harvested. Mature soft shoots similar to the rejuvenated shoots were collected from the 23-year-old stock tree. 

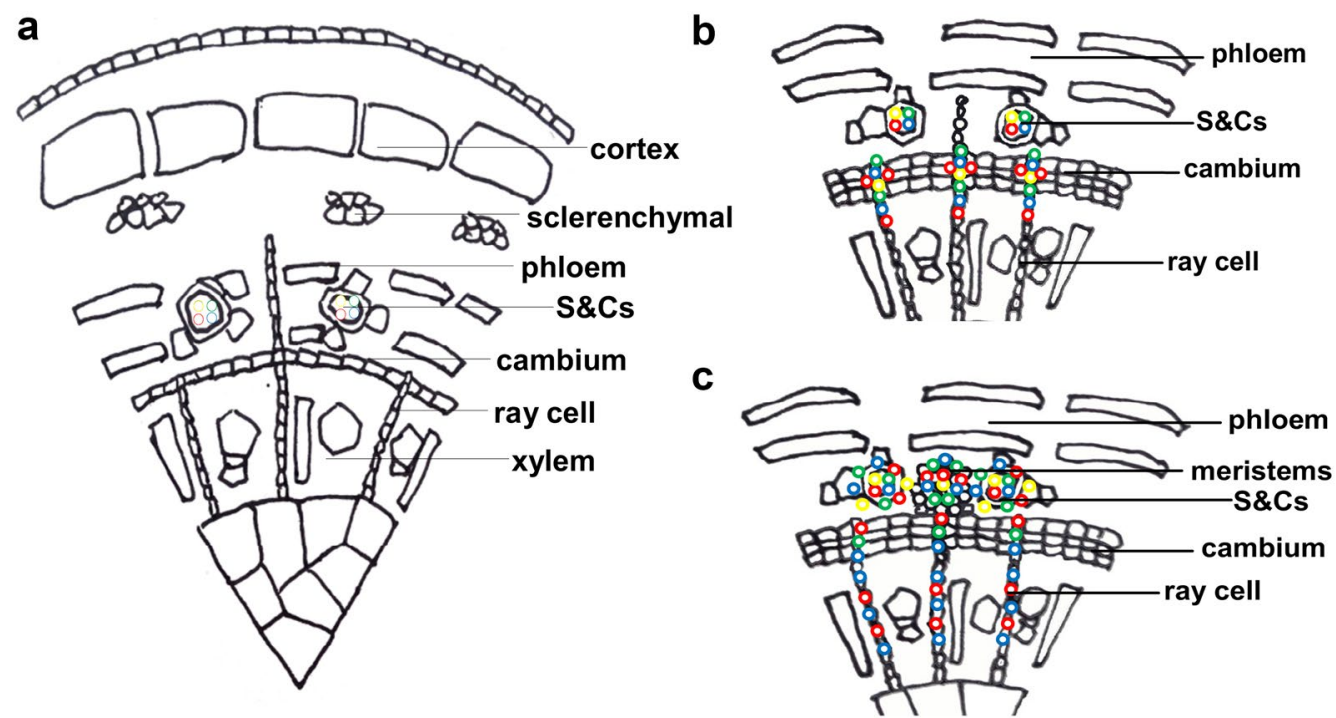

Fig. 8 A model of phytohormone distributions during the formation of root primordia. The critical periods of adventitious root induction were 1 day $(\mathbf{a}), 4$ days $(\mathbf{b})$, and 5 days (c). a At 1 day of induction, all four types of phytohormones were mainly distributed in S\&Cs. b As the cambium thickened, the phytohormones were transferred to the cambium cells. $\mathrm{GA}_{3}$ and ZR were also present in ray cells. $\mathbf{c}$ When the meristem cells began to rapidly divide, the four types of phytohormones were mainly distributed in meristems. In addition, the $\mathrm{GA}_{3}$ and ZR levels rose further in ray cells. $S \& C s$ sieve and companion cells, green color $=I A A$, yellow color $=A B A$, red color $=G A_{3}$, blue color $=Z R$

Both of the soft shoots bases were dipped in the rooting induction solution $[9 \mathrm{mM}$ IBA in $30 \%(\mathrm{v} / \mathrm{v})$ ethanol in water] for $30 \mathrm{~s}$ and submerged $6-8 \mathrm{~cm}$ in the root development medium. The shoots were exposed to natural sunlight. The humidity was maintained at about $80 \%$ by automatic intermittent spraying. The temperature of the root medium was maintained at $23 \pm 5{ }^{\circ} \mathrm{C}$ to allow rooting induction. The rooting rates were measured 5 , 10,15 , and 20 days after rooting induction. A minimum of 30 soft shoots were collected at each time point to measure rooting rates. All results are expressed as means ( \pm standard errors) of data from at least three replicate experiments. Adventitious roots were directly counted in 5-40 mm regions of basal shoots.

\section{Morphological and anatomical observations}

Ten basal segments (each $1 \mathrm{~cm}$ in length) of soft shoots were harvested every day for 15 days after rooting induction. The shoots were immediately washed with distilled water, wiped and divided into two groups. All materials were immediately fixed in FAA [freshly prepared $5 \%$ $(\mathrm{v} / \mathrm{v})$ formaldehyde, $5 \%(\mathrm{v} / \mathrm{v})$ acetic acid, and $70 \%(\mathrm{v} / \mathrm{v})$ ethanol] for at least $24 \mathrm{~h}$, dehydrated through a series of ethanol baths $[70,85,95$, and $100 \%$ (all v/v)], cleared in dimethylbenzene and embedded in paraffin. Transverse Sects. $(8 \mu \mathrm{m}$ in thickness) were prepared using a rotary microtome (RM 2245RT, Leica, Wetzlar, Germany), transferred to glass slides, dried overnight, stained with
$0.1 \%(w / v)$ toluidine blue (Sigma, St. Louis, MO, USA) for $1 \mathrm{~min}$, rinsed in distilled water, dried, dewaxed in xylene and mounted. Photomicrographs were taken (BX4112P02 instrument, Olympus, Tokyo, Japan). Three replicates of each sample were evaluated.

\section{In-situ endohormone assays}

All endohormones immunolocalization in serial sections were performed using the same microscopic phase. Antibodies were used to localize endogenous IAA, ABA, $\mathrm{GA}_{3}$ and $\mathrm{ZR}$ during rhizogenesis, using an immunohistochemical approach. Excised samples (approximately $5 \mathrm{~mm}$ in length) were rapidly immersed in a freshly prepared 2\% (w/v) aqueous solution of 1-ethyl-3-(3-dimethylaminopropyl) carbodiimide (EDC, Sigma Chemical, St. Louis, MO, USA) for $2 \mathrm{~h}$ under vacuum (-0.1 Mpa), post-fixed overnight in a solution of $4 \%(\mathrm{v} / \mathrm{v})$ paraformaldehyde and $2 \%(\mathrm{w} / \mathrm{v})$ glutaraldehyde at $4{ }^{\circ} \mathrm{C}$, rinsed in phosphate buffer $(0.2 \mathrm{M}, \mathrm{pH} 7.2)$, and dehydrated in a graded series of ethanol baths $[70,85,95$, and $100 \%$ twice (v/v)]. For immunohistochemical observations under a light microscope, all samples were embedded in paraffin and $8 \mu \mathrm{m}$ thick transverse sections were prepared using the rotary RM 2245RT microtome. The sections were transferred to glass slides, dried overnight at $37^{\circ} \mathrm{C}$, deparaffinized with xylene, and hydrated in a series of ethanol/water baths. The immunolocalization of endohormones was achieved using the method of Gao et al. 
[17], with slight modifications. The slides were incubated for $15 \mathrm{~min}$ in a blocking solution [0.05 M Tris-HCL pH 7.6, 0.3\% (v/v) Triton X-100 (Sigma-Aldrich), 10\% (v/v) normal goat serum and $5 \%(\mathrm{w} / \mathrm{v})$ bovine serum albumin], and then kept for $2 \mathrm{~h}$ at $37^{\circ} \mathrm{C}$ with primary antibodies against IAA, ABA, $\mathrm{GA}_{3}$, or $\mathrm{ZR}$ [polyclonal bovine serum albumin (Sigma-Aldrich) conjugates, Agrisera $A B$, Vännäs, Sweden]. Subsequently, the sections were briefly washed [0.05 M Tris-HCL buffer $\mathrm{pH} 7.6$ (TBS), 0.3\% (v/v) Triton X-100], blocked once again and incubated for $1 \mathrm{~h}$ at $37^{\circ} \mathrm{C}$ with gold-labeled goat anti-rabbit IgG or goat anti-rat IgG (Sigma-Aldrich) diluted 1:50 in the TBS/BSA solution. After washing, all sections underwent the silverenhancement reaction in an appropriate staining solution [0.1 M citrate buffer ( $\mathrm{pH} 3.5), 1.7 \%(\mathrm{w} / \mathrm{v})$ hydroquinone, $0.1 \%(\mathrm{w} / \mathrm{v})$ silver nitrate, $5 \%(\mathrm{w} / \mathrm{v})$ acacia]. As the color developed, the sections were rinsed twice in water, dehydrated, mounted, observed, and photographed using a microscope (BX51-DP25, Olympus).

The negative controls were as follows: first, EDC was omitted during prefixation, second, the primary antibodies were omitted, and third, the secondary antibodies were omitted (see Additional file 1: Fig. s1). All other procedures were identical to those described above. Three replicates of all samples were evaluated. Under the light microscope, any red dots were eliminated as false-positive results.

\section{Semi-quantification of endohormone levels}

The silver particles revealed the distributions of endohormones in soft shoots. To quantify these distributions, the densities of silver particles were measured by observing 30 visual fields of each tissue under an oil lens $(\times 100$ objective lens, $\times 10$ ocular lens, BX51-DP25 \& DP2-BSW lenses, Olympus). In situ immunolocalization signals were detected using automated image processing software. The mean integrated optical densities (IODs) of silver particles were quantified using ImagePro Plus (version 6.0, Media Cybernetics Inc. Bethesda, MD, USA). The IODs of silver particles were measured, as described by Taylor and Levenson [47] and Wang et al. [51], with slight modifications. Three repeated measurements were performed for all slides. All data were subjected to the analysis of variance. A P value $<0.05$ was considered to reflect a significant difference.

\section{Additional file}

Additional file 1. This file contains two figures as follows. Figure S1. Controls of endohormone immunolocalization technique. Figure S2. Comparison of Fig. 6a and f.

\section{Abbreviations}

ABA: abscisic acid; ARF: adventitious root formation; CTK: cytokinin; EDC: 1-ethyl-3-(3-dimethylaminopropyl) carbodiimide; FAA: formalin-acetic acidalcohol; GA: gibberellin; IAA: indole-3-acetic acid; IBA: indole-3-butanoic acid; IOD: integrated optical densities; S\&Cs: sieve and companion cells; ZR: zeatin riboside.

\section{Authors' contributions}

HL performed the histological examination of the walnut, and was a major contributor in writing the manuscript. YG analyzed and interpreted the IOD data regarding the phytohormones, and was a secondary contributor in writing the manuscript. XS participated in sample collection, and was a third contributor in writing the manuscript. QM and JZ participated in the thesis revision. DP was a experimental designer, and was a corresponding author. All authors read and approved the final manuscript.

\section{Author details}

${ }^{1}$ State Key Laboratory of Tree Genetics and Breeding, Research Institute of Forestry, Chinese Academy of Forestry, Beijing 100091, China. ${ }^{2}$ College of Horticulture and Landscape, Tianjin Agricultural University, Tianjin 300384, China.

\section{Acknowledgements}

The authors gratefully acknowledge Mr. Huzhi Xu for helpful comments.

\section{Competing interests}

The authors declare that they have no competing interests.

\section{Availability of data and materials}

The data generated or analysed during this study are included in this published article and its supplementary information files.

\section{Consent for publication}

All authors have given consent for the manuscript.

Ethics approval and consent to participate Not applicable.

Funding

National Natural Science Foundation of China (31672126).

\section{Publisher's Note}

Publisher's NoteSpringer Nature remains neutral with regard to jurisdictional claims in published maps and institutional affiliations.

Received: 28 August 2017 Accepted: 3 February 2018

Published online: 09 February 2018

\section{References}

1. Amissah JN, PaolilloJr DJ, Bassuk N. Adventitious root formation in stem cuttings of Quercus bicolor and Quercus macrocarpa and its relationship to stem anatomy. J Am Soc Hortic Sci. 2008;133:479-86.

2. Basheer-Salimia R. Juvenility, maturity, and rejuvenation in woody plants. Hebron Univ Res J. 2007:3:17-43.

3. Björklund S, Antti H, Uddestr I, Moritz T, Sundberg B. Cross-talk between gibberellin and auxin in development of Populus wood: gibberellin stimulates polar auxin transport and has a common transcriptome with auxin. Plant J. 2007;52(3):499-511.

4. Busov V, Meilan R, Pearce DW, Rood SB, Ma C, Tschaplinski TJ, Strauss SH. Transgenic modification of gai or rg/1 causes dwarfing and alters gibberellins, root growth, and metabolite profiles in Populus. Planta. 2006;224:288-99.

5. Chang IF, Chen PJ, Shen CH, Hsieh TJ, Hsu YW, Huang BL, Kuo Cl, Chen YT, Chu HA, Yeh KW, Huang LC. Proteomic profiling of proteins associated with the rejuvenation of Sequoiasempervirens (D. Don) Endl. Proteome Sci. 2010;8:64-79.

6. Chutinanthakun T, Sekozawa Y, Sugaya S, Gemma H. Effect of bending and the joint tree training system on the expression levels of $G A_{3}$-and 
$G A_{2}$-oxidases during flower bud development in 'Kiyo' Japanese plum. Sci Hortic. 2015;193:308-15.

7. Dawood T, Yang XP, Visser EJW, et al. A co-opted hormonal cascade activates dormant adventitious root primordia upon flooding in Solanum dulcamara. Plant Physiol. 2016;170(4):2351-64.

8. Day ME, Greenwood MS, Diaz-Sala C. Age-and size-related trends in woody plant shoot development: regulatory pathways and evidence for genetic control. Tree Physiol. 2002;22:507-13.

9. De Almeida MR, de Bastiani D, Gaeta ML, de Araújo Mariath JE, de Costa F, Retallick J, Nolan L, Tai HH, Strömvik MV, Fett-Neto AG. Comparative transcriptional analysis provides new insights into the molecular basis of adventitious rooting recalcitrance in Eucalyptus. Plant Sci. 2015;239:155-65.

10. De Diego N, Rodríguez JL, Dodd IC, Pérez-Alfocea F, Moncaleán P, Lacuesta M. Immunolocalization of IAA and ABA in roots and needles of radiata pine (Pinus radiate) during drought and rewatering. Tree Physiol. 2013;33:537-49.

11. Della Rovere F, Fattorini L, D'Angeli S, Veloccia A, Falasca G, Altamura MM. Auxin and cytokinin control formation of the quiescent centre in the adventitious root apex of Arabidopsis. Ann Bot. 2013;1 (12):1395-407.

12. Dong NG, Pei D, Yin WL. Tissue-specific localization and dynamic changes of endogenous IAA during poplar leaf rhizogenesis revealed by in situ immunohistochemistry. Plant Biotechnol Rep. 2012;6:165-74.

13. Dong NG, Yin WL, Gao Y, Pei D. Indole-3-acetic acid accumulation during poplar rhizogenesis revealed by immunohistochemistry. Biol Plantarum. 2012:56(3):581-4.

14. Dong NG, Gao Y, Hao YB, Yin WL, Pei D. Subcellular localization of endogenous IAA during poplar leaf rhizogenesis revealed by in situ immunocytochemistry. Plant Biotechnol Rep. 2014;8:377-86.

15. Falasca G, Reverberi M, Lauri P, Caboni E, De Stradis A, Altamura MM. How agrobacterium rhizogenes triggers de novo root formation in a recalcitrant woody plant: an integrated histological, ultrastructural and molecular analysis. New Phytol. 2000;145(1):77-93.

16. Ford YY, Taylor JM, Blake PS, Marks TR. GibberellinA3 stimulates adventitious rooting of cuttings from cherry (Prunus avium). Plant Growth Regul. 2002;37:127-33.

17. Gao Y, Liu H, Pei D. Morphological characteristics and in situ auxin production during the histogenesis of staminate flowers in precocious walnut. J Am Soc Hortic Sci. 2014;139(2):185-90.

18. Gao Y, Liu H, Dong NG, Pei D. Temporal and spatial pattern of indole3-acetic acid occurrence during walnut pistillate flower bud differentiation as revealed by immunohistochemistry. J Am Soc Hortic Sci. 2012;137:283-9.

19. Giovannelli A, Giannini R. Reinvigoration of mature chestnut (Castanea sativa) by repeated graftings and micropropagation. Tree Physiol. 2000;20(18):1243-8.

20. Hu X, Xu L. Transcription factors WOX 11/12 directly activate WOX5/7 to promote root primordia initiation and organogenesis. Plant Physiol. 2016;172:2363-73.

21. Huang HJ, Chen Y, Kuo JL, Kuo TT, Tzeng CC, Huang BL, Chen CM, Huang LC. Rejuvenation of Sequoia sempervirens in vitro: changes in isoesterases and isoperoxidases. Plant Cell Physiol. 1996;37:77-80.

22. Huang LC, Chow TY, Tseng TC, Kuo Cl, Liu SM, Ngoh MG, Murashige T, Huang $\mathrm{HJ}$. Association of mitochondrial plasmids with rejuvenation of the coastal redwood, Sequoia sempervirens (D. Don) Endl. Bot Bull Acad Sin. 2003:44:25-30.

23. Huang LC, Lius S, Huang BL, Murashige T, Mahdiel FM, Van Gundy R. Rejuvenation of Sequoia sempervirens by repeated grafting of shoot tips onto juvenile rootstocks in vitro: model for phase reversal of trees. Plant Physiol. 1992;98:166-73.

24. Huang Y, Ji KS, Zhai JR. Relationship between rooting ability and endogenous phytohormone changes in successive continuous generation cuttings of Buxussinica var. parvifolia, an endangered woody species in China. For Stud China. 2007;9(3):189-97.

25. Husen A. Rejuvenation and adventitious rooting in coppice-shoot cuttings of Tectona grandis as affected by stock-plant etiolation. Am J Plant Sci. 2011;2:370-4.

26. Kelen M, Ozkan G. Relationships between rooting ability and changes of endogenous IAA and ABA during the rooting of hardwood cuttings of some grapevine rootstocks. Eur J Hortic Sci. 2003;68(1):8-13.
27. Kim JS, Jung HJ, Lee HJ, Kim KA, Goh CH, Woo Y, Oh SH, Han YS, Kang H. Glycine-rich RNA-binding protein7 affects abiotic stress responses by regulating stomata opening and closing in Arabidopsis thaliana. Plant J. 2008:55:455-66.

28. Kim JY, Kim WY, Kwak KJ, Oh SH, Han YS, Kang H. Glycine-rich RNA-binding proteins are functionally conserved in Arabidopsis thaliana and Oryza sativa during cold adaptation process. J Exp Bot. 2010;61(9):2317-25.

29. Liu J, Sheng L, Xu Y, Li J, Yang Z, Huang H, Xu L. WOX 11 and 12 are involved in the first-step cell fate transition during de novo root organogenesis in Arabidopsis. Plant Cell. 2014;26(3):1081-93.

30. Löfke C, Zwiewka M, Heilmann I, Van Montagu MC, Teichmann T, Frim J. Asymmetric gibberellin signaling regulates vacuolar trafficking of PIN auxin transporters during root gravitropism. Proc Natl Acad Sci. 2013;110(9):3627-32.

31. Materán ME, Fernández M, Valenzuela S, Sáez K, Seemann P, SánchezOlate M, Ríos D. Abscisic acid and 3-indolacetic acid levels during the reinvigoration process of Pinus radiata D. Don adult material. Plant Growth Regul. 2009;59(2):171-7.

32. Mauriat M, Petterle A, Bellini C, Moritz T. Gibberellins inhibit adventitious rooting in hybrid aspen and Arabidopsis by affecting auxin transport. Plant J. 2014;78(3):372-84.

33. Maynard BK, Bassuk NL, Maynard BK. Effects of stock plant etiolation, shading, banding, and shoot development on histology and cutting propagation of Carpinus betulus L. fastigiata. J Am Soc Hortic Sci. 1996;121:853-60.

34. Negishi N, Nakahama K, Urata N, Kojima M, Sakakibara H, Kawaoka A. Hormone level analysis on adventitious root formation in Eucalyptus globules. New For. 2014;45(4):577-87.

35. Niu S, Li Z, Yuan H, Fang P, Chen XY, Li W. Proper gibberellin localization in vascular tissue is required to regulate adventitious root development in tobacco. J Exp Bot. 2013;64(11):3411-24.

36. Ondzighi-Assoume CA, Chakraborty S, Harris JM. Environmental nitrate stimulates abscisic acid accumulation in Arabidopsis root tips by releasing it from inactive stores. Plant Cell. 2016;28(3):729-45.

37. Pacurar DI, Perrone I, Bellini C. Auxin is a central player in the hormone cross-talks that control adventitious rooting. Physiol Plantarum. 2014;151:83-96.

38. Pei D, Yuan LC, Xi SK, Gu RS. Shoot rooting in vitro for walnut cultivars. Sci Silvae Sin. 2001;38(2):32-7.

39. Perrin Y, Doumas P, Lardet L, Carron MP. Endogenous cytokinins as biochemical markers of rubber-tree (Hevea brasiliensis) clone rejuvenation. Plant Cell Tissue Organ Cult. 1997;47:239-44.

40. Petridou M, Voyiatzis DG. Difficult-to-root cv. kalamon can easily be propagated by softwood layers with an improved method of moundlayering. Acta Hortic. 2002;586:915-8.

41. Pijut PM, Woeste KE, Michler CH. Promotion of adventitious root formation of difficult-to-root hardwood tree species. Hortic Rev. 2011;38:213-51.

42. Poethig RS. Phase change and the regulation of developmental timing in plants. Science. 2003;301:334-6.

43. Saini S, Sharma I, Kaur N, Pati PK. Auxin: a master regulator in plant root development. Plant Cell Rep. 2013;32:741-57.

44. Sen S, Kazankaya A, Testereci H, HakkiYörük I. Changing of IAA (indol3 -acetic acid) content at different organs of walnut (Juglans regia L.) after grafting. Acta Hort. 1997;442(23):169-74.

45. Sukumar P, Maloney GS, Muday GK. Localized induction of the ATP-binding cassette B19 auxin transporter enhances adventitious root formation in Arabidopsis. Plant Physiol. 2013;162(3):1392-405.

46. Tartoura KAH. Effect of abscisic acid on endogenous IAA, auxin protector levels and peroxidase activity during adventitious root initiation in Vigna radiata cuttings. Acta Physiol Plant. 2001;23(2):149-56.

47. Taylor CR, Levenson RM. Quantification of immunohistochemistry-issues concerning methods, utility and semiquantitative assessment II. Histopathology. 2006;49:411-24.

48. Vahdati K, Leslie C, Zamani Z, McGranahan G. Rooting and acclimatization of in vitro-grown shoots from mature trees of three Persian walnut cultivars. HortScience. 2004;39(2):324-7.

49. Vahdati K, Rezaee R, Grigoorian V, Valizadeh M, Motallebi Azar A. Rooting ability of Persian walnut as affected by seedling vigour in response to stool layering. J Horti Sci Biot. 2008;83(3):334-8. 
50. Von Aderkas P, Bonga JM. Influencing micropropagation and somatic embryogenesis in mature trees by manipulation of phase change, stress and culture environment. Tree Physiol. 2000;20(14):921-8.

51. Wang CJ, Zhou ZG, Holmqvist A, Zhang H, Li Y, Adell G, Sun XF. Survivin expression quantified by image pro-plus compared with visual assessment. Appl Immunohistochem Mol Morphol. 2009;17:530-5.

52. Wei C, Zhang X, Qi G, Li B, Sun M, Qi J. Effects of bending branch and notching buds in different periods on endogenous hormone concentrations and shoot growth of 'Lüling' walnut. Sci Silvae Sin. 2013;49:167-71.

53. Wendling I, Trueman SJ, Xavier A. Maturation and related aspects in clonal forestry - part II: reinvigoration, rejuvenation and juvenility maintenance. New For. 2014;45(4):473-86
54. Willige BC, Isono E, Richter R, Zourelidou M, Schwechheimer C. Gibberellin regulates PIN-FORMED abundance and is required for auxin transportdependent growth and development in Arabidopsis thaliana. Plant Cell. 2011;23(6):2184-95.

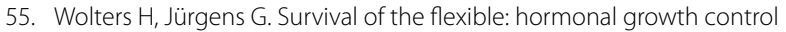
and adaptation in plant development. Nat Rev Genet. 2009;10:305-17.

56. Zhang M, Han M, Ma F, Shu H. Effect of bending on the dynamic changes of endogenous hormones in shoot terminals of 'Fuji' and 'Gala' apple trees. Acta Physiol Plant. 2015;37(4):1-9.

\section{Submit your next manuscript to BioMed Central and we will help you at every step:}

- We accept pre-submission inquiries

- Our selector tool helps you to find the most relevant journal

- We provide round the clock customer support

- Convenient online submission

- Thorough peer review

- Inclusion in PubMed and all major indexing services

- Maximum visibility for your research

Submit your manuscript at www.biomedcentral.com/submit 